\title{
Depositional influences on Re-Os systematics of late Cretaceous-Eocene coals and carbonaceous mudstones, Taranaki Basin, New Zealand
}

ENOCK ROTICH ${ }^{1}$, MONICA HANDLER ${ }^{1}$, RICHARD SYKES ${ }^{2}$, DAVID SELBY $^{3,4}$, SEBASTIAN NAEHER ${ }^{2}$

${ }^{1}$ School of Geography, Environment and Earth Sciences, Victoria University of Wellington, PO Box 600, Wellington, 6140, New Zealand

${ }^{2}$ GNS Science, 1 Fairway Drive, PO Box 30368, Lower Hutt, 5040, New Zealand

${ }^{3}$ Department of Earth Sciences, Durham University, Durham, DH1 3LE, UK

${ }^{4}$ State Key Laboratory of Geological Processes and Mineral Resources, School of Earth Resources, China University of Geosciences, Wuhan, 430074, Hubei, China

We present Re-Os, total sulfur and bulk pyrolysis data for late Cretaceous-Eocene coals and carbonaceous mudstones from the Taranaki Basin, New Zealand, to investigate factors controlling Re-Os systematics in near-shore to fully terrestrial organic-rich sedimentary rocks. Samples from the late Cretaceous Rakopi Formation (Fm) exhibit radiogenic initial ${ }^{187} \mathrm{Os} /{ }^{188} \mathrm{Os}\left(\mathrm{Oss}_{\mathrm{i}}\right)$ values $(0.8-1.2)$, typical for terrestrial coals that mainly source Os from weathering of the upper continental crust (UCC). In contrast, samples from the latest Cretaceous to Eocene North Cape, Farewell and Mangahewa formations show non-radiogenic Osi values (0.3-0.5), which we attribute to variable proportions of plant- and seawaterderived Os, and influence of open and restricted waterways.

Marine transgressions can result in significant enrichment of Re and Os in coals ${ }^{[1]}$, however, the average Re and Os concentrations for the strongly marine-influenced coals from the Eocene Mangahewa Fm are very low $(0.51 \pm 0.47 \mathrm{ppb}$ and $29.7 \pm 18.1 \mathrm{ppt}$, respectively), and comparable to those of the UCC. Despite the lack of significant $\mathrm{Re}$ and Os enrichment, strong positive correlations between total sulfur and Re and Os concentrations in these coals suggest probable derivation of these elements from seawater, an interpretation supported by the similarity of the coals' Osi to that of the seawater at the time of deposition.

The Paleocene Farewell Fm samples were selected specifically to test Re-Os geochronology in terrestrial sediments. The data, however, exhibit significant scatter with no discernible linear trend, which we attribute primarily to a lack of spread in the ${ }^{187} \mathrm{Re} /{ }^{188} \mathrm{Os}$ ratios.

[1] Tripathy et al., 2015, Earth and Planetary Science Letters, 432, 13-237 